\title{
Tracking students' progress through the Spanish university school sector
}

\author{
Gérard LASSIBILLE \\ IREDU-CNRS, Université de Bourgogne, France
}

Lucía NAVARRO GÓMEZ

Facultad de Ciencias Económicas y Empresariales, Departamento de Estadística y Econometría, Universidad de Málaga, Spain

Article publié dans Higher Education, 2009, vol.58, $n^{\circ} 6$, pp.821-839

DOI $10.1007 / \mathrm{s} 10734-009-9227-8$

\begin{abstract}
:
From individual longitudinal data for a full cohort of first-entering students who embarked on short programs in Spain and were observed over a 7-year period ending in 2003, we analyze the probability that an individual will drop out, transfer, or graduate from a university school program. The statistical analysis is carried out in a competing- risks framework. We find that the system's internal efficiency is low, with dropout and completion rates averaging 50 and 36\%, respectively. However, we find considerable variability in the probabilities of withdrawal, transfer, and graduation among students. In this regard, our results show that preenrollment academic ability, age at enrollment, family characteristics, and secondary educational experience are major influences on student progress.
\end{abstract}

\section{Introduction}

Higher education in Spain attracts a large proportion of high school graduates, and at this level of schooling the gross enrollment ratio is among the highest in the European Union, with around twothirds of the population in the corresponding age group enrolled in an institution of higher education (Unesco 2007). Although international comparisons place the country in a relatively favorable position, two rough indices suggest, however, that the performance of the sector is probably low: around two-thirds of all students enrolled in the last grade of a higher education program withdraw or repeat the grade, and only one-third of the students who graduate do so in the intended time frame.

In this context, dropping out, transferring, and progressing slowly toward a degree have severe consequences for the individuals involved as well as for the society that finances most of the cost of service delivery. Having a better understanding of how students' enrollment decisions end is thus important in maximizing the use of resources allocated to education and in supporting the development of retention strategies that help to improve the education system's performance. For these reasons, numerous economic and sociological studies are devoted to completion and to students' dropout behavior (see, for example, Blanchfield 1972; Booth and Satchell 1995; Desjardins et al. 1999; Mallete and Cabrera 1991; Tinto 1987). Due to the lack of appropriate data, there is no such study for Spain. This article attempts to fill this gap by analyzing the incidence, timing, and determinants of student departure in the university school sector - a sector that enrolls nearly half of all the new entrants in the Spanish higher education system.

Unlike countries such as the United States or the United Kingdom, large-scale micro data on university students are not yet available in Spain. For this reason, and following the vast majority of the empirical work performed to date on student departure, our research is conducted on a single 
institution. The information refers to the whole population of first-year entrants in a large public Spanish university, who were observed over a 7-year period ending in June 2003. Based on this unique data set, which describes the school career of new entrants in more than 20 short academic programs, we use a competing-risks framework to estimate discrete-time hazard models of the decision to exit a program via alternative routes. The results may be suggestive for the individual student and potentially for university authorities and educational planners in designing policies and initiating interventions to prevent students from leaving the higher education system before completion. Beyond that, the results raise important questions about the effectiveness of the current policies that regulate student flows in higher education and so can help policy makers to identify and put in place reforms that improve the education system's performance.

The remainder of the paper is organized as follows. "Institutional context" briefly documents the organization of the Spanish higher education sector. "Data and variables" describes the data, together with a discussion of the variables. "Methodological approach" presents the econometric model. "Empirical results" presents estimates of the determinants of dropout, transfer, and completion probabilities based on a competing-risks model. "Conclusion" draws some conclusions and policy implications.

\section{Institutional context}

Higher education in Spain offers three distinct tracks that emphasize either academic or vocational subjects. Students may pursue long-cycle programs offered by the conventional facultades (university faculties). Today the university faculties account for a little more than $50 \%$ of the students in higher education. University faculties are entitled to offer studies in all branches of knowledge, with the exception of technologies. Long- cycle programs at university faculties last between 4 and 6 years, depending on the discipline and the university, and lead to a licenciado degree (licentiate degree). Long-cycle professional programs are offered at the escuelas técnicas superiores (higher technical schools) and lead to ingeniero (engineering) and arquitecto (architectural) degrees; they require 5 to 6 years of study. Around $10 \%$ of students in higher education are enrolled in higher technical schools. Short-cycle degree programs are offered at the escuelas universitarias (university schools). The studies undertaken at these colleges last 3 years, and graduates receive the degree of diplomado (university graduate), ingeniero técnico (engineering technician), or diplomado arquitecto técnico (architectural technician). The programs offer a wide range of subjects, including fine arts, information technology, library science, nursing, allied health, social work, business studies, teaching at the basic education level, technical engineering, and architecture. Today, the university school sector enrolls around 570,000 students and accounts for $38 \%$ of all the students in higher education. A remarkable trend in recent years is the increase in the number of new entrants into the university school sector. Over the space of less than 10 years, the share of entering freshmen enrolled in short programs has risen from 42 to $49 \%$, while in the same time period the percentage of entering students enrolled in faculty programs has fallen $16 \%$.

Admission to faculties and higher technical schools is based on the Prueba de Acceso para la Universidad, an entrance exam conducted by the higher education institutions themselves. ${ }^{1}$ Because of the huge demand for higher education and the limited number of places, nearly all universities in the last few years have established admission quotas, using the entrance exam as the basis. Admission to short-cycle degree programs is generally much less selective. Students who have completed the Curso de Orientación Universitaria (COU) and students with a vocational education degree may enter a university school without sitting for the entrance exam. However, a system of preselection exists for entry into almost all short-cycle programs, with final selection determined on

1 Students who sit for the Prueba de Acceso para la Universidad have completed general upper-secondary education and a 1-year period known as the Curso de Orientación Universitaria (university orientation course). 
the basis of the results obtained during the COU. Most long and short programs are based on a credit system. Generally, no strict measures limit the length of time in which students must complete their courses. In some cases, students are permitted to repeat up to six times in any given subject.

At the macro level, very little information is available on the internal efficiency of the Spanish higher education system. No systematic information is collected to follow the schooling career of higher education students, and data published by the Ministry of Education do not make it possible to measure the system's student flow efficiency. In what follows, we put together various pieces of information pertaining to the number of graduates and the time-to-degree by sector (Table 1). The information available nationwide, while admittedly incomplete and imperfect, ${ }^{2}$ suggests that the performance of the higher education system as a whole, and that of the university school sector in particular, is low. According to the Ministry of Education (Ministerio de Educación y Ciencia 2001), $70 \%$ of the first-year entrants in engineering university schools drop out. The ratio graduates/ student in the university school sector is around $15 \%$, while under fixed cohort size this ratio would be roughly $33 \%$. We estimate that a little more than one-third of the students enrolled in the last year of a university school program graduate, while two-thirds repeat or drop out. Although we have no benchmarks for identifying an ideal level of production, this rate of graduation appears relatively low compared to that of the faculty sector, where more than $50 \%$ of students enrolled in the last year of a program complete their studies. With regard to time-to-degree, results in Table 1 show that less than $40 \%$ of the 2003-2004 degree recipients at university schools were able to graduate within the intended period of time, while nearly $30 \%$ required 6 years and more to earn a diploma.

Table 1 The production of graduates by sector, 2003-2004 (unless otherwise indicated)

\begin{tabular}{lllll}
\hline & $\begin{array}{l}\text { University } \\
\text { schools }\end{array}$ & Faculties & $\begin{array}{l}\text { Higher technical } \\
\text { schools }\end{array}$ & Total \\
\hline Graduates/students enrolled in last grade (\%) & 35.8 & 57.3 & 35.0 & 43.5 \\
$\begin{array}{l}\text { Graduates/total enrollment (\%) } \\
\text { Dropout rate (\%) }\end{array}$ & 75.3 & 10.6 & 12.9 & 13.7 \\
Time-to-degree & & ND & ND & ND \\
Average time (years) & 4.7 & 6.8 & 7.8 & - \\
Graduates by years of graduation (\%) & & & & 31.0 \\
$\quad$ Within the intended time frame & 38.2 & 26.6 & 31.0 & 21.2 \\
$\quad$ One year more & 20.4 & 21.7 & 21.2 & 15.6 \\
$\quad$ Two years more & 13.3 & 16.3 & 15.6 & 32.2 \\
$\quad$ Three years and more & 28.1 & 35.3 & 32.2 & \\
\hline
\end{tabular}

Sources: Ministerio de Educación y Ciencia (2001, 2006)

a Engineering university schools only; the result pertains to the 1995-1996 cohort of first-year entrants in 49 institutions (see Ministerio de Educación y Ciencia 2001-Annex Table II-E)

b The data refer to various cohorts of freshmen who graduate during the same school year; in this case, timeto-degree may be influenced by the size of each entering cohort. The date of entry in the various higher education programs is missing for more than $20 \%$ of the 2003-2004 graduates. We address the problem by distributing the missing values in proportion to time-to-degree; by doing so, we assume that the Registrar's Office has a greater probability of reporting a missing date of entry for cohorts of older students

2 No information is available on dropout and repetition. Precise information on the distribution of students by grade is also lacking, and the distribution of graduates by year of entry into the program is generally poorly documented. 


\section{Data and variables}

The data for our analysis come from administrative records maintained at the Registrar's Office of the University of Málaga and from data recorded at the Ministry of Education of the Autonomous Government of Andalusía. Apart from detailed transcript data from first year to dropout or graduation, the database extracted from these registries also describes the personal characteristics and family background of students when they enter the university, measures of their secondary educational experience, and information on whether the students were accepted into their preferred course of study and whether they received financial support at each point in time.

The data cover the full population of first-time-in-university school students entering at the University of Málaga at the start of the 1996 academic year-that is, around 3,000 students enrolled in 22 programs. ${ }^{3}$ These students were observed until September 2003 - that is, for a total of seven full school years. Withdrawal from a course is inferred from enrollment patterns. Students who have a period of non-enrollment between periods of enrollment are excluded, due to data limitations. ${ }^{4}$ Although students may drop out at any time during the academic year, due to lack of information, we measure time until withdrawal as the number of years from the first year of enrollment in the program. A completion is assumed to occur only at the end of a year, and the time taken to complete a program is the number of years from commencement until the time enrollment ceases. For the students who are still enrolled and have not achieved the degree by the date of our last observation, we mark the duration as censored at this point.

\section{The incidence of dropout, transfer, and graduation}

Table 2 provides some information about unconditional and conditional dropout rates for the 1996 cohort of new entrants into university schools. Overall dropout is defined as withdrawal from a degree program for whatever reason. The unconditional overall dropout rate is the proportion of first-year entrants who left the program within our study period. The conditional overall dropout rate is the proportion of students known to be enrolled at the beginning of a particular year who left by the end of that year. In Table 2 we break down the overall dropout rates by reason for the withdrawal and make a distinction between students who drop out due to course changes and students who withdraw for reasons other than program transfers. To complete the picture, the table also shows the unconditional and the conditional completion rates of the entering cohort, the percentage of students who are still enrolled in the program before the end of data collection, the timing of the dropout decision for those students who quit the program, and the time-to-completion for students who graduate.

Results in Table 2 confirm our expectations: the internal efficiency of the university school sector is low: 51\% of all students who started a degree program in 1996 dropped out, 36\% graduated, and $13 \%$ were still enrolled in the program at the time of the survey. Looking more closely at the dropout pattern by year, we see that the conditional overall dropout rate declines quite dramatically as students progress through the program. By the end of the first year, university school students have a dropout probability of $31 \%$ compared with 10 and $6 \%$ by the end of the second and third year, respectively.

Overall, transfers only account for around $20 \%$ of all withdrawals. The unconditional probability of exiting from a program because of course transfer is, as expected, lower than the unconditional probability of withdrawing for other reasons. Most of the transfers occur early in the student's

3 The University of Málaga enrolls more than 38,000 students; it is one of the eight largest public institutions in the country. Although there is no precise information to compare the performance of students in Málaga, we consider, overall, that this institution is fairly representative of the Spanish higher education system. To illustrate, the graduates/student ratio is around $12 \%$ at Málaga, compared to 13 at the system level.

4 We roughly estimate that less than $2 \%$ of entering students stop out during the 7 -year period of observation. 
career. By the end of the first year, university school students have a probability of transfer of around $8 \%$ compared with 2 and $1 \%$ by the end of the second and third year, respectively.

Results in Table 2 also show that few students are able to complete the requirements for a degree within the minimum degree time frame. Overall, $48 \%$ of university school students take 3 years to earn a diploma, while $19 \%$ of graduates need one additional year to complete a degree, and $33 \%$ require two additional years or more to graduate. On average, students who embark on a short higher education program take a little more than 4 years to earn a diploma.

Table 2 Schooling career of new entrants to university schools

\begin{tabular}{|c|c|c|c|c|c|}
\hline & \multicolumn{5}{|l|}{ Mode of exit } \\
\hline & \multicolumn{3}{|c|}{ Reason for dropout } & \multirow[t]{2}{*}{ Graduate } & \multirow[t]{2}{*}{ Total } \\
\hline & Overall dropout & Transfer & Other reasons & & \\
\hline Unconditional rate $(\%)$ & 50.5 & 10.2 & 40.3 & 36.3 & 86.8 \\
\hline \multicolumn{6}{|l|}{ Conditional rate $(\%)$} \\
\hline Year 1 & $30.6(60.7)$ & $7.7(75.8)$ & $22.9(56.8)$ & - & $30.6(35.3)$ \\
\hline Year 2 & $10.0(13.7)$ & $2.0(13.8)$ & $7.9(13.7)$ & - & $10.0(8.0)$ \\
\hline Year 3 & $6.1(7.6)$ & $1.2(7.4)$ & $4.9(7.6)$ & $27.8(47.9)$ & $34.0(24.4)$ \\
\hline Year 4 & $6.3(5.2)$ & $0.7(2.7)$ & $5.7(5.8)$ & $16.8(19.0)$ & $23.1(11.0)$ \\
\hline Year 5 & $6.4(4.0)$ & $0.0(0.0)$ & $6.4(5.0)$ & $18.9(16.5)$ & $25.2(9.2)$ \\
\hline Year 6 & $8.6(4.0)$ & $0.1(0.3)$ & $8.4(4.9)$ & $17.1(11.2)$ & $25.7(7.0)$ \\
\hline Year 7 & $14.0(4.9)$ & $0.0(0.0)$ & $14.0(6.1)$ & $11.3(5.5)$ & $25.3(5.1)$ \\
\hline Mean time to exit (years) & 2.1 & 1.4 & 2.3 & 4.1 & 2.5 \\
\hline Percent of all withdrawals & 100.0 & 20.2 & 79.8 & - & \\
\hline Censored observations (\%) & 13.2 & & & & \\
\hline Cohort size & 2,909 & & & & \\
\hline
\end{tabular}

Figures in parentheses refer to the percentage of students who withdraw, transfer, or graduate by year

\section{Explanatory variables}

Table 3 presents the summary statistics of the variables for our data set, with means and SDs shown for the full cohort of first entrants in university schools. The table also gives the percentage of students who graduate and drop out by their reason for withdrawal, for each selected variable.

According to Table 3, enrollments in university schools are distributed equally across gender; however, male students are more likely to drop out than female students. In Spain, the official starting age for higher education is 18 . Results indicate that the average age of entry into a university school program exceeds this standard by 2 years. Two-thirds of the students who enter at the age of 20 or more withdraw; their completion rate is 2.3 times lower than that of students who enter at the age of 18 or younger. Results show that university school students are particularly prone to postpone enrollment after completing upper-secondary or vocational education: $18 \%$ of new entrants in short programs are delayers. ${ }^{5}$ Parental education is often found to be one of the most important family-related factors in explaining dropout and completion (see, for example, Manski et al. 1999; Smith and Naylor 2001). In this regard, a striking aspect of the information in Table 3 is

5 In a companion paper (Lassibille and Navarro 2008), we show that $8 \%$ of new entrants in university faculties and $3 \%$ of new entrants in higher technical schools are delayers. 
that students enrolled in university schools tend to come mainly from more disadvantaged families, as seen by the relatively small number of fathers with an upper-secondary or a higher education. We use scores achieved on the pre-university exam to control for students' pre-enrollment academic abilities. Since selection and entry requirements differ widely by subject and because students differ widely in ability, we normalize the scores within subject. ${ }^{6}$ In our sample, about one-third of students gain admission following secondary vocational education. On average, $26 \%$ of them graduate and $57 \%$ drop out or transfer, whereas $42 \%$ of students who enroll after completing general secondary do so. In a system based on entrance quotas, many students do not get into their first choice of course at the university. In this regard, results in Table 3 indicate that $41 \%$ of students enrolled in short programs are not satisfied with the subject they are enrolled in, compared with 59\% who are. Turning now to the time-varying enrollment variable, which represents information available after students have enrolled in a particular program, Table 3 shows that $40 \%$ of the university school students receive grant support during their schooling career. ${ }^{7}$ According to our estimations, of the students who receive state grants, $46 \%$ drop out and $29 \%$ graduate; these proportions are 58 and $29 \%$, respectively, for the students who do not receive financial support.

6 Normalized score at pre-university exam $=(X-M) / S$, where $X$ is the student's score on the pre-university exam, $M$ is the average score of students taking the same subject, and $\mathrm{S}$ is the SD.

7 State support grant is "means-tested" on family income but is in addition payable only to those students with a specified minimum level of exam performance. Note that the amount of financial aid students received is not available in our data set. 
Table 3 Means and SDs of variables in the sample

\begin{tabular}{|c|c|c|c|c|c|c|c|}
\hline & \multirow[t]{3}{*}{ Mean } & \multirow[t]{3}{*}{ SD } & \multicolumn{5}{|c|}{$\begin{array}{l}\text { Percentage of students who leave the program by } \\
\text { mode of exit }\end{array}$} \\
\hline & & & \multicolumn{3}{|c|}{ Reason for dropout } & \multirow[t]{2}{*}{ Graduate } & \multirow[t]{2}{*}{ Tota } \\
\hline & & & $\begin{array}{l}\text { Overall } \\
\text { dropout }\end{array}$ & Transfer & $\begin{array}{l}\text { Other } \\
\text { reasons }\end{array}$ & & \\
\hline \multicolumn{8}{|l|}{ Subject area ${ }^{a}$} \\
\hline $\begin{array}{l}\text { Economics and business } \\
\text { administration }\end{array}$ & 0.378 & 0.485 & 57.2 & 9.8 & 47.4 & 30.4 & 87.6 \\
\hline Education & 0.186 & 0.389 & 24.1 & 3.7 & 20.4 & 73.9 & 98.0 \\
\hline Health & 0.075 & 0.264 & 15.1 & 0.5 & 14.6 & 82.2 & 97.3 \\
\hline Engineering & 0.361 & 0.480 & 64.4 & 16.0 & 48.4 & 13.6 & 78.0 \\
\hline \multicolumn{8}{|l|}{ Gender } \\
\hline Male & 0.492 & 0.500 & 59.5 & 12.9 & 46.5 & 22.9 & 82.4 \\
\hline Female & 0.508 & 0.500 & 41.8 & 7.6 & 34.2 & 49.4 & 91.2 \\
\hline Age at enrollment (in years) & 20.156 & 2.997 & - & - & - & - & - \\
\hline \multicolumn{8}{|l|}{ Distribution by age at enrollment } \\
\hline$\leq 18$ years old & 0.296 & 0.456 & 33.1 & 12.6 & 20.6 & 53.7 & 86.8 \\
\hline $18-20$ years old & 0.404 & 0.491 & 51.3 & 11.2 & 40.1 & 33.6 & 84.9 \\
\hline$>20$ years old & 0.301 & 0.459 & 66.5 & 6.6 & 59.9 & 23.0 & 89.5 \\
\hline \multicolumn{8}{|l|}{ Enrollment timing in higher education } \\
\hline Delayed enrollment & 0.180 & 0.384 & 62.5 & 5.0 & 57.6 & 26.6 & 89.1 \\
\hline Continuous enrollment & 0.820 & 0.384 & 47.9 & 11.4 & 36.5 & 38.5 & 86.4 \\
\hline $\begin{array}{l}\text { Normalized score at preuniversity } \\
\text { exam }\end{array}$ & 0.000 & 0.996 & - & - & - & - & - \\
\hline \multicolumn{8}{|c|}{ Distribution by normalized score at preuniversity exam } \\
\hline 1st quartile (low) & 0.255 & 0.436 & 69.4 & 12.7 & 56.7 & 15.4 & 84.8 \\
\hline 2nd quartile & 0.249 & 0.433 & 54.9 & 13.5 & 41.4 & 30.9 & 85.8 \\
\hline 3rd quartile & 0.252 & 0.434 & 46.4 & 8.6 & 37.8 & 39.2 & 85.6 \\
\hline 4th quartile (high) & 0.244 & 0.429 & 30.9 & 5.9 & 25.0 & 60.0 & 90.9 \\
\hline \multicolumn{8}{|c|}{ Diploma when entering into higher education } \\
\hline Vocational education diploma & 0.370 & 0.483 & 63.4 & 6.5 & 56.9 & 26.5 & 89.9 \\
\hline $\begin{array}{l}\text { General upper-secondary } \\
\text { diploma }\end{array}$ & 0.630 & 0.483 & 42.9 & 12.4 & 30.5 & 42.1 & 85.0 \\
\hline \multicolumn{8}{|l|}{ Student's preference } \\
\hline Studying chosen subject & 0.594 & 0.491 & 50.2 & 9.1 & 41.1 & 35.3 & 85.5 \\
\hline Not studying chosen subject & 0.406 & 0.491 & 50.9 & 11.8 & 39.2 & 37.9 & 88.8 \\
\hline \multicolumn{8}{|l|}{ Father's education level } \\
\hline $\begin{array}{l}\text { Primary education completed } \\
\text { or less }\end{array}$ & 0.583 & 0.493 & 55.2 & 8.4 & 46.8 & 35.9 & 91.1 \\
\hline Lower-secondary education & 0.133 & 0.340 & 49.1 & 9.5 & 39.7 & 37.6 & 86.7 \\
\hline Upper-secondary education & 0.088 & 0.284 & 51.8 & 16.0 & 35.8 & 30.0 & 81.8 \\
\hline Higher education & 0.126 & 0.332 & 46.7 & 12.8 & 33.9 & 38.5 & 85.2 \\
\hline Unknown & 0.070 & 0.255 & 52.2 & 8.9 & 43.3 & 41.4 & 93.9 \\
\hline
\end{tabular}




\begin{tabular}{|c|c|c|c|c|c|c|c|}
\hline & \multirow[t]{3}{*}{ Mean } & \multirow[t]{3}{*}{$\mathrm{SD}$} & \multicolumn{5}{|c|}{$\begin{array}{l}\text { Percentage of students who leave the program by } \\
\text { mode of exit }\end{array}$} \\
\hline & & & \multicolumn{3}{|c|}{ Reason for dropout } & \multirow[t]{2}{*}{ Graduate } & \multirow[t]{2}{*}{ Total } \\
\hline & & & $\begin{array}{l}\text { Overall } \\
\text { dropout }\end{array}$ & Transfer & $\begin{array}{l}\text { Other } \\
\text { reasons }\end{array}$ & & \\
\hline \multicolumn{8}{|l|}{ Location } \\
\hline Institution's hometown & 0.483 & 0.500 & 51.8 & 11.0 & 40.8 & 36.4 & 88.2 \\
\hline Other & 0.517 & 0.500 & 49.3 & 9.4 & 39.8 & 36.3 & 85.6 \\
\hline \multicolumn{8}{|l|}{ State financial support ${ }^{\mathrm{b}}$} \\
\hline Receiving support & 0.401 & 0.416 & 46.3 & 8.4 & 37.9 & 40.1 & 86.4 \\
\hline Not receiving support & 0.599 & 0.416 & 57.6 & 13.2 & 44.1 & 29.1 & 86.7 \\
\hline Number of students & 2,909 & - & 1,469 & 297 & 1,172 & 1,057 & 2,526 \\
\hline Percent of total cohort & - & - & 50.5 & 10.2 & 40.3 & 36.3 & 86.8 \\
\hline
\end{tabular}

\section{Methodological approach}

It is important to keep in mind that several of the variables listed above (for example, subject area, delayed enrolment, financial support) are likely to be endogeneous. The endogeneity of independent variables is a common problem to all studies on student progress through higher education programs, and only a small number of them deal with potential endogeneity of the regressors (see for example, Alon 2007). Like the vast majority of studies performed on the topic, the information at our disposal refers to variables available at the time of the students' application only. Because our sources do not contain the necessary instruments, we are not able to control for possible endogeneity of the variables, and to correct for eventual self-selection biases. Otherwise stated, we are able to identify correlations but we are not necessarily able to identify causal relations between variables. This limitation is of no great consequence if interest centers on predictive power of the variables. From this point of view, the analyses we perform show that administrative records provide a rich source of data for detailed analysis of student progress, and that this information may help admissions offices to predict students' performance in higher education.

We model the decisions to exit the educational system via the three alternative routes as discretetime hazard models. As explained earlier, we know the year in which students drop out, transfer, or graduate, but we do not know the exact date when these events occur. Otherwise stated, these events are interval-censored events. In this case, the standard approach to modeling the hazard, $\mathrm{h}(\mathrm{j})$ - - that is, the conditional probability that a student will withdraw, transfer, or graduate from a program in the time interval $\mathrm{j}$ given that he has not yet left the program - is to use the discrete-time analogue of the continuous-time proportional hazards model with a complementary log-log (clog-log) transformation:

$$
\log \{-\log [1-\mathrm{h}(\mathrm{j})]\}=\alpha_{\mathrm{j}}+\beta^{\prime} \mathrm{X}
$$


where $X$ is a vector of time-invariant and time-varying covariates, $\beta$ is a vector of regression coefficients, and $\alpha_{\mathrm{j}}=\log \left\{-\log \left[1-\mathrm{h}_{0}(\mathrm{t})\right]\right\}$ is the complementary $\log -\log$ transformation of the baseline hazard arising when $\mathrm{X}=0$. The baseline hazard is specified as a piecewise-constant function - that is, a step function of time. Then, the full model specification is:

$$
\log \{-\log [1-\mathrm{h}(j)]\}=\sum_{l=1}^{J} \alpha_{l} \delta_{l}+\beta^{\prime} X
$$

where $\delta$ are dummy variables corresponding to each time period, $\alpha$ are parameters to be estimated, and $J$ is the last time period observed in the sample.

The model specification considered above implicitly assumes that the explanatory variables exhaust all the sources of individual variation in the hazard rates. Obviously, this is rarely the case: individuals differ in so many ways that no finite set of covariates can capture all the differences between them. Failure to control for any unobserved individual- specific effects that may affect the hazard functions can produce severe bias in the structural estimates of duration models. ${ }^{8}$ For this purpose, we extend the previous model by including a random error term along with the vector of characteristics, and we allow for unobserved heterogeneity or frailty by assuming that the error term is normally distributed with mean zero and finite variance.

Like most studies on student departure, we assume that the hazards of each competing risk are mutually independent ${ }^{9}$ - that is, we fit the discrete-time proportional hazard models presented above by running separate regressions for the probability of withdrawal, transfer, and completion, treating the other events as censored. To do so, we reorganize the original sample by expanding the data into person-period form, ${ }^{10}$ and we create destination-specific censoring indicators. The analysis includes all students, and a panel of individuals is constructed with the $i$ th individual contributing $j=1,2, \ldots$, $t_{i}$ observations. The maximum number of periods (years) that an individual can be at risk is seven.

\section{Empirical results}

Following the analytical framework described above, Table 4 shows separate regressions of the conditional probabilities of leaving a program via the three modes of exit. ${ }^{11}$ Because the programs cannot be completed before the end of 3 years, the conditional probability of successfully completing the program is estimated for students who are at risk of graduation at time $j=3$ and beyond. The models employ a general specification of time using a separate dummy variable for each time period; to save space, the coefficients of the time dummies are not shown. The models are fitted without and with unobserved heterogeneity. The $\sigma$ coefficients reported in Table 4 are SDs of the heterogeneity variances. The reported $\rho$ are the proportions of the total variance contributed by the panel-level variance component.

8 Many studies on students' departure do not account for unobserved heterogeneity (see for example, Bozick and DeLuca 2005; Chizmar 2000; Ronco 1996); others have found it to be insignificant (see for example, Arulampalam et al. 2001).

9 We do so because of the simplicity in estimating the discrete-time hazard models. The existing literature on students' withdrawal and completion is divided on the issue of dependence of these two outcomes. For example, Desjardins et al. (1999) estimate both independent and dependent competing-risk models for the probability of stopout and completion; they find little difference between the two specifications.

10 The final data set contains 10,070 person-period records on 2,909 persons.

11 To save space, the results of the single-risk model showing the effect of each covariate on the conditional probability of leaving the program for whatever reason are not presented. They are available from the authors upon request. 
The model $\chi^{2}$ statistics indicate that the regressions are significant at standard levels. The likelihood ratio tests for $\rho$ in Table 4 suggest statistically significant frailty with a non-negligible panel-level variance component. This result implies that ignoring unobserved heterogeneity may create misleading conclusions about the determinants of the probabilities of exit to the competing states and the timing of the decision to drop out or to graduate. In the remainder of this discussion, we focus on the results that take into account unobserved heterogeneity.

Because a student may leave the educational system via alternative routes $\mathrm{r}$ in time interval $j$, we use the results in Table 4 to estimate the marginal effect of each covariate on the conditional probability of exit via each of theses routes (denoted $P_{r}(j)$ ), the unconditional exit probabilities via each state (denoted $\Pi_{\mathrm{r}}$ ), and the time until exit via each route (denoted $E_{\mathrm{r}}$ ). In what follows, the marginal effects on the conditional probabilities of exit are computed by evaluating the baseline hazards at the sample means and for $j=3$ (the duration of the program). Following Thomas (1996), we simulate the marginal effect of covariate $x$ on the unconditional probabilities of exit and the expected waiting time until exit. To do so, we compute $\Pi_{\mathrm{r}}$ and $E_{\mathrm{r}}$ at the sample means for continuous variables and zero for dummy covariates and then resimulate by increasing the continuous variables by one SD and by setting each dummy variable equal to one.

Based on estimation results in Table 4 that take into account unobserved heterogeneity, Table 5 shows the marginal effects of each covariate on the conditional and unconditional probabilities of exit and on the time until exit. It also shows the corresponding parameter estimate of the relevant covariate on the conditional probability that a student exits via risk $\mathrm{r}$ in time interval $j$ given that he or she has not yet left the program. Coefficient estimates are reported as odds ratios; values above 1.0 identify predictors that increase the risk of exiting.

Table 4 Clog-log hazard models of the probabilities of leaving the program via three modes of exit

\begin{tabular}{|c|c|c|c|c|c|c|}
\hline & \multicolumn{3}{|c|}{ Without unobserved heterogeneity } & \multicolumn{3}{|c|}{ With unobserved heterogeneity } \\
\hline & Dropout & Transfer & Graduate & Dropout & Transfer & Graduate \\
\hline \multicolumn{7}{|l|}{ Subject area ${ }^{a}$} \\
\hline Education & $-0.747^{* * *}$ & $-0.879 * * *$ & $1.060^{* * *}$ & $-0.811^{* * *}$ & $-0.964^{* * *}$ & $1.349^{* * *}$ \\
\hline Health & $-0.706^{* * *}$ & $-2.799 * * *$ & $0.893 * * *$ & $-0.735^{* * * *}$ & $-2.921^{* * *}$ & $1.123^{* * *}$ \\
\hline Engineering & $0.143^{*}$ & $0.473^{* * *}$ & $-1.247^{* * *}$ & $0.145^{*}$ & $0.543^{* k *}$ & $-1.430^{* * *}$ \\
\hline Male & -0.001 & -0.006 & $-0.333^{* * *}$ & 0.008 & 0.009 & $-0.369^{* * *}$ \\
\hline \multicolumn{7}{|l|}{ Age at enrollment } \\
\hline $18-20$ years old & $0.276^{* * *}$ & -0.128 & $-0.415^{* * *}$ & $0.277^{* * *}$ & -0.142 & $-0.478^{* * *}$ \\
\hline$>20$ years old & $0.630^{* * 4}$ & -0.225 & $-0.756^{* * *}$ & $0.664^{* * 4 *}$ & -0.258 & $-0.872^{* * *}$ \\
\hline Delayed enrollment & $0.270^{* * *}$ & $-0.550^{* *}$ & 0.098 & $0.318^{* * *}$ & $-0.647^{* * *}$ & 0.088 \\
\hline Normalized score at preuniversity exam & $-0.196^{* * *}$ & $-0.207^{* * *}$ & $0.333^{* * * *}$ & $-0.216^{* * *}$ & $-0.230^{* * *}$ & $0.411^{* * *}$ \\
\hline Entering with vocational education diploma & $0.680^{* * 4}$ & $-0.275^{*}$ & -0.087 & $0.766^{* * *}$ & $-0.327^{*}$ & -0.105 \\
\hline Studying chosen subject & $-0.201 * * *$ & $-0.412^{* * *}$ & 0.056 & $-0.225^{* * *}$ & $-0.466 * * *$ & 0.057 \\
\hline \multicolumn{7}{|l|}{ Father's education level ${ }^{\mathrm{b}}$} \\
\hline Lower-secondary education & -0.081 & 0.100 & 0.120 & -0.076 & 0.084 & 0.147 \\
\hline Upper-secondary education & $-0.250^{* *}$ & 0.271 & -0.022 & $-0.289^{* *}$ & 0.305 & -0.048 \\
\hline Higher education & $-0.184^{*}$ & $0.312^{*}$ & $0.215^{* *}$ & $-0.195^{*}$ & 0.322 & $0.234^{*}$ \\
\hline Resident of the institution's hometown & 0.011 & $0.288^{* *}$ & -0.011 & 0.017 & $0.317^{* *}$ & 0.001 \\
\hline Receiving state financial support & $-0.303^{* * *}$ & $0.430^{* * 4}$ & $1.113^{* * * *}$ & $-0.318^{* * *}$ & $0.355^{* 4 * *}$ & $1.118^{* * *}$ \\
\hline Intercept & $-1.660^{* * *}$ & $-3.005 * * *$ & $-1.633^{* * *}$ & $-1.796^{* * *}$ & $-3.373^{* * *}$ & $-1.832^{* * *}$ \\
\hline$\sigma$ & - & - & - & 0.543 & 1.087 & 0.582 \\
\hline$\rho$ & - & - & - & 0.152 & 0.418 & 0.171 \\
\hline LR for $\rho$ & - & - & - & 7.320 & 29.379 & 21.157 \\
\hline Log likelihood & -3092.356 & -1190.926 & -1896.960 & -3088.696 & -1176.237 & -1886.381 \\
\hline Model $\chi^{2}$ & $1058.9^{* * * *}$ & $296.4^{* * 4}$ & $1430.9^{* * *}$ & $912.4^{* * *}$ & $196.2^{* * *}$ & $902.7^{* * * *}$ \\
\hline
\end{tabular}




\begin{tabular}{|c|c|c|c|c|c|c|}
\hline & \multicolumn{3}{|c|}{ Without unobserved heterogeneity } & \multicolumn{3}{|c|}{ With unobserved heterogeneity } \\
\hline & Dropout & Transfer & Graduate & Dropout & Transfer & Graduate \\
\hline Number of students & 2,909 & 2,909 & 1,817 & 2,909 & 2,909 & 1,817 \\
\hline Number of student-period records & 10,070 & 10,070 & 5,143 & 10,070 & 10,070 & 5,143 \\
\hline
\end{tabular}

What do the estimates reveal about withdrawal, transfer, and completion among university school students? For the sake of clarity, we discuss the results presented in Table 5 in two parts. In the first, we consider the reasons for leaving the program (that is, dropout and transfer); in the second part, we discuss completion.

\section{Correlates and timing of the dropout and transfer decisions}

The results show that, all else remaining the same, students in education and health have lower hazard rates, lower conditional probabilities of exiting for whatever reason at time $\mathrm{j}$ given the termination of study at time $\mathrm{j}$, and much smaller unconditional probabilities of dropout and transfer compared with their peers. The estimated models also suggest that students in education and health who withdraw are characterized by much shorter expected durations of study relative to the base of economics and business administration. ${ }^{12}$ A noteworthy feature in the results is that students in engineering are particularly prone to drop out compared with their peers; all else remaining the same, they also have an expected time-to-dropout much higher than their counterparts.

With respect to gender, we note that, although female students in university schools are, on average, less likely to drop out than male students (see Table 3), there is no significant gender difference in the probability of withdrawal after controlling for personal characteristics. This result is consistent with the findings from most studies on student departure. More often than not, no gender effect is found to be significant when considering the withdrawal decision of students. However, most studies show that females are more likely to graduate and earn degrees faster than males, after controlling for other factors. ${ }^{13}$

Because students who are older at the time of enrollment have higher opportunity costs and a shorter time over which they may receive a benefit in return of their investment, one may expect that these students are less likely to complete their studies and have a higher probability of dropping out. In this regard, results in Table 5 show that age at enrollment is positively associated with dropping out. To illustrate, our estimates indicate that students age 20 or older have an unconditional probability of dropping out $0.26 \%$ point higher than students age 18 or younger. According to our calculations, older students also spend more time studying in the program before dropping out than their counterparts, ceteris paribus. Overall, these results are consistent with the findings from other studies on the determinants of withdrawal from post-compulsory education (see, for example, Murtaugh et al. 1999). However, we find no evidence that age at enrollment exerts a significant influence on the probability of transfer to another program.

All else remaining the same, delaying entry to higher education significantly decreases the risk of transfer among university school students, while it has a stronger and significant positive effect on their risk of dropping out. These findings are at odds with the commonly held belief that such a pattern of enrollment is associated with socioeconomic constraints and academic marginality that

12 Students who transfer stay longer in the program, too.

13 This last finding is at odd with what we observe in Spain (see our discussion below). 
are detrimental to the student's progress. According to our results, delaying entry reduces both the expected duration of study conditional on dropping out and the expected duration of study conditional on transfer, although the impact on the timing of the decision to withdraw is much greater than the effect on the timing of the decision to transfer.

With regard to the other influences on the probabilities of dropping out, the regression results indicate that preenrollment academic abilities are a powerful predictor of the probability of withdrawal. All else remaining the same, an advantage of one SD above the sample mean in the preuniversity exam score reduces the unconditional probabilities of dropping out by $0.27 \%$ point. This is an important conclusion in the Spanish context, where the volume of students who leave secondary education with a diploma is expected to increase in the future, in response to policies recently introduced to ensure that a larger proportion of students complete their secondary education. In light of our results, reducing the entry standards to satisfy the demand for higher education from an increasing pool of secondary-school leavers who are not necessarily equipped with the basic skills needed to succeed in higher education would have an adverse effect. In this context, tighter selection at the entry point of university school programs might be needed.

As described in "Data and variables" of this paper, about one-third of entering students in university schools gain admission following secondary vocational education, while the other twothirds enroll in short higher education programs after completing general secondary education. According to Table 5, students entering with a vocational education diploma are particularly prone to withdraw, with an unconditional probability of dropping out that is $0.26 \%$ point greater than that of students entering with a secondary general education. Although our results show that students entering with a vocational education diploma have a shorter expected duration of withdrawal, this huge gap raises serious questions about the capacity of the vocational education system to prepare students adequately for higher education studies.

An equally important result is that students who do not get into the course they want are at higher risk of leaving both the program and the institution before completion, ceteris paribus. However, the impact of this variable is small. We estimate that the unconditional probabilities of withdrawal and transfer are, respectively, 0.05 and $0.02 \%$ point greater for dissatisfied students than for students who are in their preferred course of study. Obviously, this evidence raises questions about the effectiveness of the placement of students and shows that current admission policies do not reduce the risk of dropping out but instead may create frustration among the affected individuals. In this regard, a noteworthy feature in the results is that students who get into the course they want are characterized by longer expected durations of withdrawal and transfer, in contrast with students who are not in their preferred course.

Regarding financial support, the results show that students who receive state grants are less likely than students who do not receive state grants to withdraw or transfer. This result is consistent with other findings documenting the impact of financial aid on college behavior (see, for example, Dynarski 1999; or Edlin 1993). It implies that financial support not only boosts the demand for education, by reducing the opportunity cost of studies, but also helps to reduce the flow of students who leave the program before completion.

Father's level of education accounts for the genetic ability of students and serves also as a predictor of the parent's potential market earnings that could be invested in schooling. Results in Table 5 show that this variable tends to reduce dropping out and that second-generation students - that is, students whose parents graduated from higher education-as well as students whose father has an upper-secondary education have lower conditional and unconditional probabilities of withdrawal, ceteris paribus. Finally, the results show that students whose parents are residents of the institution's home-town are more likely to transfer than students who are not residents, ceteris paribus. The intuition of this result is clear if we think about the costs of attendance that non-resident families have to finance. 


\section{Correlates and timing of completion}

Recall that completion is modeled for students who are potentially at risk of graduation - that is, for students who neither drop out nor transfer before time $\mathrm{j}=3$. Under these circumstances, the results show that male students are less likely to complete their studies than female students. Our calculations also show that male students take somewhat longer to earn a degree compared with female students.

With regard to the impact of age at enrollment, results in Table 5 suggest that this variable decreases significantly the probability of completion and that age at enrollment is associated with slower progress toward the degree. To illustrate, students age 20 and older at enrollment have an unconditional probability of graduation $0.30 \%$ point lower than students who are 18 or younger at the time of enrollment. We estimate that, all else remaining the same, they also have an expected duration of study conditional on completion 0.26 year longer than their counterparts.

The regression results indicate that preenrollment academic abilities, as measured by the score on the pre-university examination, are a powerful predictor of completion. ${ }^{14}$ All else remaining the same, an advantage of one SD above the sample mean in the pre-university exam score increases the unconditional probability of graduation by $0.38 \%$ point. It also shortens the expected time-tocompletion by more than 1 year.

Turning to financial support, the results show that students who receive state grants are more likely to exit via graduation than their counterparts, ceteris paribus. According to our calculations, their unconditional probability of completion is $0.29 \%$ point higher than that of their peers. Receiving support also reduces the time-to-degree by about 0.5 year relative to the average time required by individuals who never receive a grant during their schooling career. Although our results clearly suggest that "means-tested" support does have a very important impact on students from low income families, an issue that needs to be addressed is how the dollar level of support really affects graduation and students' time-to-degree, and what is the optimal level of student support. Obviously, more data are needed to analyze these issues.

Finally, the results show that, after controlling for ability, preferences, and socio-economic characteristics, significant differences do exist across subject areas. All else remaining the same, students in education and health have higher unconditional probabilities of completion than students in economics and business administration. They also finish faster than their counterparts, with a time saving varying between 0.6 and 0.7 year, depending on the type of program. On the contrary, students in engineering perform significantly worst than their peers. We estimate that their unconditional probability of graduation is $0.35 \%$ point lower than that of their counterparts. Students in this field of study are also characterized by greater expected time-to-degree. These findings raise important questions about the management of the pedagogical processes in the various fields of study. In this regard, the remaining disparities in performance across subjects may be telltale signs of differences in the effectiveness with which the available educational inputs are managed to promote student learning and how teachers use their instructional time and how they manage their classes. They also may be attributable to the specificities of the subject matter, which can be more or less difficult depending on the field of study.

It is also interesting to consider the variables that do not affect completion. In this regard several features in the results are noteworthy. All else remaining the same, students who have delayed entry to the program do not have a significantly lower probability of graduation than their counterparts. Furthermore, students who gain admission following secondary vocational education, as well as those who do not get into the course they want, do not perform significantly worse than their peers. These results are because a large proportion of students with such individual characteristics have dropped out or transferred before the standard length of the university school programs - that is,

14 As shown by Dolton et al. (2003) abilities directly constraint students performance, and this is largely unaffected by extra time allocated to self study. 
before time $\mathrm{j}=3$. To illustrate, $54 \%$ of students who enter with a secondary vocational education diploma withdraw or transfer in the first 3 years of observation, compared with only $34 \%$ of those who enter with a secondary general education. A similar proportion of delayers leave the program during this period, while only $38 \%$ of students who do not experience discontinuity between completion of secondary school and enrollment in higher education do so. One main implication from the results reported here is that any program designed to improve completion must reduce withdrawal rates in the early part of the program. For this reason, university schools could map specific academic support plans for these at-risk students in order to stimulate their effort and performance at the beginning of their schooling career.

\section{Conclusion}

In this paper, we have applied discrete-time survival analysis to explain why university school students drop out, transfer, or graduate. Although the study was conducted with data from a single institution, they shed light on the system's performance. As indicated previously, our results pertain to students enrolled in more than 20 programs, and for this reason it is very unlikely that our conclusions reflect differences in the nature of graduate programs offered at this one institution.

When describing the data, we found that the incidence of dropping out is particularly high. At the time of the survey, half of the cohort of students had dropped out or transferred and less than $40 \%$ had graduated. We also found that, as students progress through the program, their conditional probabilities of withdrawal decrease dramatically. A noteworthy feature in the results is that less than $50 \%$ of university school graduates are able to complete the requirements for a degree within the minimum time frame.

Among other results, we found that, all else remaining the same, female students are more likely to graduate than male students and that age at enrollment is a powerful indicator of withdrawal and completion. However, we found no evidence that age at enrollment exerts a significant influence on the probability of transfer to another program. Students who delay entry into higher education, as well as students who do not get into the course they want, are at higher risk of leaving both the program and the institution. However, these variables have a virtually zero effect on completion, because a large proportion of students with these individual characteristics drop out or transfer before the standard length of the university school programs. We have also shown that students entering with a vocational education are not sufficiently equipped with the basic skills needed to succeed in higher education. Academic preparedness was found to be a powerful determinant of the students' behavior. In this regard, our estimations showed that an advantage of one SD above the sample mean in the pre-university exam score increases the unconditional probability of graduation by $0.38 \%$ point and shortens the expected time-to-completion by more than 1 year. We also found that, after controlling for ability, preferences, and socio-economic characteristics, significant differences do exist across subject areas. Obviously, these findings raise important questions about the management of the pedagogical processes in the various fields of study. More research and more data clearly are needed to analyze this issue.

Several implications for the development of education policy arise from the foregoing results. The first is the need for continued efforts to raise survival rates in higher education. In this regard, universities could design and develop retention and graduation interventions for at-risk students; such targeted programs would benefit both the students and the institutions. One main implication from our results is that any academic support plan designed to improve completion should try to reduce the withdrawal rates of at-risk students in the early part of the program by stimulating their effort and performance from the beginning of their schooling career. To increase the flow of graduates from a given cohort of students, policy makers could consider administrative measures such as more systematic and tighter criteria for selecting the intake into higher education. In this 
regard, admission of students with a vocational educational diploma could be limited to students with good prior academic performance. Strict measures designed to limit the excessive length of time students are allowed to complete their courses should be considered too. These interventions could improve the system's performance. In the context of a meaningful expansion in the number of high school graduates, these interventions could also be one way to manage the increased pressures put on the higher education system. But equally relevant could be measures that encourage greater cost-consciousness among individuals and their families as they make educational choices at the higher education level, including greater cost sharing by students in public higher education, with appropriate features to minimize any adverse impact on those from low-income families.

\section{Acknowledgments}

The research was funded in part through a research support grant from the Ministry of Education (no. SEJ2007-68045-CO2-01/ECON).

\section{References}

Alon, S. (2007). The influence of financial aid in leveling group differences in graduating from elite institutions. Economics of Education Review, 26, 296-311. doi:10.1016/j.econedurev.2006.01.003.

Arulampalam, W., Naylor, R. A., \& Smith, J. P. (2001). A hazard model of the probability of medical school dropout in the United Kingdom. IZA DP 333. Bonn.

Blanchfield, W. (1972). College dropout identification: An economic analysis. The Journal of Human Resources, 7(4), 540-544. doi:10.2307/144756.

Booth, A. L., \& Satchell, S. E. ((1995)). The hazards of doing a Ph.D.: An analysis of completion, withdrawal rates of British Ph.D. students in the 1980s. Journal of the Royal Statistical Society Series A, 158, 297-318. (statistics in society).

Bozick, R., \& DeLuca, S. (2005). Better late than never? Delayed enrollment in the high school to college transition. Social Forces, 84(1), 531-554. doi:10.1353/sof.2005.0089.

Chizmar, J. (2000). A discrete-time hazard analysis of the role of gender in persistence in the economics major. The Journal of Economic Education, 31(2), 107-118. doi:10.2307/1183183.

Desjardins, S. L., Ahlburg, D. A., \& McCall, B. P. (1999). An event history model of student departure. Economics of Education Review, 18, 375-390. doi:10.1016/S02727757(98)00049-1.

Dolton, P., Marcenaro, O., \& Navarro, L. (2003). The effective use of student time: A stochastic frontier production function case study. Economics of Education Review, 22, 547-560. doi:10.1016/S0272- 7757(03)00027-X.

Dynarski, S. M. (1999). Does aid matter? Measuring the effect of student aid on college attendance and completion. Working Paper 7422. Cambridge, MA: National Bureau for Economic Research.

Edlin, A. (1993). Is college financial aid equitable and efficient? The Journal of Economic Perspectives, 7(2), 143-158.

Lassibille, G., \& Navarro, L. (2008). Why do higher education students drop out? Evidence from Spain. Education Economics, 16(1), 89-105. doi:10.1080/09645290701523267. 
Mallete, B. I., \& Cabrera, A. F. (1991). Determinants of withdrawal behavior: An exploratory study. Research in Higher Education, 32(2), 179-194. doi:10.1007/BF00974436.

Manski, B. I., Sandefur, G., McLanahan, S., \& Powers, D. (1999). Alternative estimates of the effects of family structure during adolescence on high school graduation. Journal of the American Statistical Association, 87(417), 25-37. doi:10.2307/2290448.

Ministerio de Educación y Ciencia. (2001). Informe transversal del rendimiento académico de las ingenierías técnicas. Madrid: Consejo de Universidad.

Ministerio de Educación y Ciencia. (2006). Estadística universitaria: Curso 2003-2004. Madrid: Consejo de Coordinación Universitaria.

Murtaugh, P. A., Burns, L. D., \& Shuster, J. (1999). Predicting the retention of university students. Research in Higher Education, 40(3), 355-371. doi:10.1023/A:1018755201899.

Ronco, S. (1996). How enrollment ends: Analyzing the correlates of student graduation, transfer, and dropout with a competing-risk model. Association for Institutional Research Professional File, 61(Summer), 1-16.

Smith, J., \& Naylor, R. (2001). Determinants of degree performance in U.K. universities: A statistical analysis of the 1993 student cohort. Oxford Bulletin of Economics and Statistics, 63(1), 29-60. doi: 10.1111/1468-0084.00208.

Thomas, J. (1996). On the interpretation of covariate estimates in independent competing risks models.

Bulletin of Economic Research, 48(1), 27-39. doi:10.1111/j.1467-8586.1996.tb00622.x.

Tinto, V. (1987). Leaving College: Rethinking the causes and cures of student attrition. Chicago: University of Chicago Press.

Unesco (2007). Education statistics. http://www.uis.unesco.org. Accessed 9 Dec 2007. 